\title{
Acute Calcific Tendinitis of the Flexor Digitorum Superficialis of the Finger: A Case Report
}

\author{
Young Sung Kim, Ho Min Lee, Jong Pil Kim* \\ Department of Orthopaedic Surgery, College of Medicine, Dongguk University, Gyeongju, South Korea \\ Email: ${ }^{*}$ kipil@dongguk.ac.kr
}

Received 28 December 2013; revised 2 February 2014; accepted 10 February 2014

Copyright (C) 2014 by authors and Scientific Research Publishing Inc.

This work is licensed under the Creative Commons Attribution International License (CC BY). http://creativecommons.org/licenses/by/4.0/

(c) (i) Open Access

\begin{abstract}
Acute calcific tendinitis of the shoulder is a well-known condition, but it is rare in the hand or finger. It is often misdiagnosed when it occurs outside the shoulder. We report an unusual case of acute calcific tendinitis of the flexor digitorum superficialis insertion of the 4th finger in a young female martial art athlete after minor trauma history, and discuss with a review of the literature.
\end{abstract}

Keywords

Calcific Tendinitis; Flexor Digitorum Superficialis; Finger

\section{Introduction}

Acute calcific tendinitis is an inflammatory disorder of the tendon or its insertion caused by calcium deposits [1]. Most commonly, acute calcific tendinitis occurs in the shoulder around the rotator cuff, but it is rare in the hand. It has been mistaken for other conditions such as acute infection [2]-[4] or fracture [5] [6]. This leads to unnecessary use of antibiotics, hospital admissions, and possibly even surgery. Acute calcific tendinitis is a self-limiting disease [1] [4]. The most common occurring site of acute calcific tendinitis of the hand is at the insertion of the flexor carpi ulnaris tendon (FCU) in peri-menopausal women [1] [4] [7] [8]. We describe an unusual case of acute calcific tendinitis of the flexor digitorum superficialis (FDS) insertion of the 4th finger in a young female martial art athlete after minor trauma initially misdiagnosed it as a fracture.

\section{Case Report}

A 22-year-old female patient was referred to our orthopaedic department from a local clinic for treatment of ${ }^{*}$ Corresponding author.

How to cite this paper: Kim, Y.S., Lee, H.M. and Kim, J.P. (2014) Acute Calcific Tendinitis of the Flexor Digitorum Superficialis of the Finger: A Case Report. Open Journal of Orthopedics, 4, 45-47.

http://dx.doi.org/10.4236/ojo.2014.43008 
what was thought to be an avulsion fracture of the finger. The patient complained of pain and a limit of motion of her left 4 th finger injured during a martial arts activity. Active and passive movement of the DIP and PIP joint were limited and painful. The finger was edematous and tender palmarly over the PIP joint, but had no erythema or local heating. She had suffered some soreness of her finger for one week prior to this injury. The patient was a practitioner of Taekwondo, Korean traditional martial art which mainly uses the legs and fists, and had a history of repeated minor trauma on her hands. A radiograph demonstrated elliptical soft tissue calcification over the palmar aspect of the middle phalanx base (Figure 1(a)). Laboratory tests, including white blood cell count, erythrocyte sedimentation rate, C-reactive protein, calcium, phosphorus and alkaline phosphatase levels, were normal. Computed tomography was obtained to rule out the avulsion fracture, and showed a round amorphous calcification on the volar aspect of the middle phalanx base (Figure 1(b)) and no evidence of avulsion fracture. A diagnosis of acute calcific tendinitis of the FDS insertion was made, and the patient was treated with finger splinting and non-steroidal anti-inflammatory medication. Two weeks later, the symptoms were completely gone and an X-ray demonstrated complete resolution of the calcification (Figure 1(c)). The calcification was not present at 6 months follow up.

\section{Discussion}

Acute calcific tendinitis was rare in hand, first described by Cohen [7] in 1924. The most common occurrence of acute calcification of the hand was at the insertion of the FCU tendon in middle aged or peri-menopausal women [1] [4] [7] [8]. Finger joints are less commonly involved, and the MP joint is the most frequently affected site followed by the PIP joint [2]. The clinical manifestations of acute calcific tendinitis of the hand include severe localized pain, swelling, tenderness, edema, erythema and loss of function [1] [2] [4] [5] [9]. Because of its rarity and its clinical resemblance to other entities, it has been frequently mistaken for other conditions such as acute infection [2]-[4] or fracture [5] [6] when it occurs outside the shoulder. In our case, the primary physician misdiagnosed this tendinitis as an FDS avulsion fracture of the middle phalanx base.

The calcium deposition was proved the hydroxyapatite crystal [3] [4]. The exact etiology of this calcium deposition is uncertain. Acute calcific tendinitis is largely idiopathic, but some reports suggested that repeated or local trauma was a cause of the calcium deposition [1] [4], while Uhthoff and colleagues [10] suggested local hypoxia due to mechanical or vascular changes may be the cause. In our case, the patient was a practitioner of martial arts. Therefore, we thought that repeated minor trauma or repeated motions were the most likely cause of calcification, and symptoms were more aggravated after injury.

Acute calcific tendinitis is a self-limiting disorder and usually resolves in 3 to 4 weeks even if not treated [1] [4]. Once the diagnosis is made, surgery is unnecessary. Conservative measures such as splinting and non-steroidal anti-inflammatory drugs are sufficient [2] [3] [5] as in our case. An intralesional corticosteroid injection

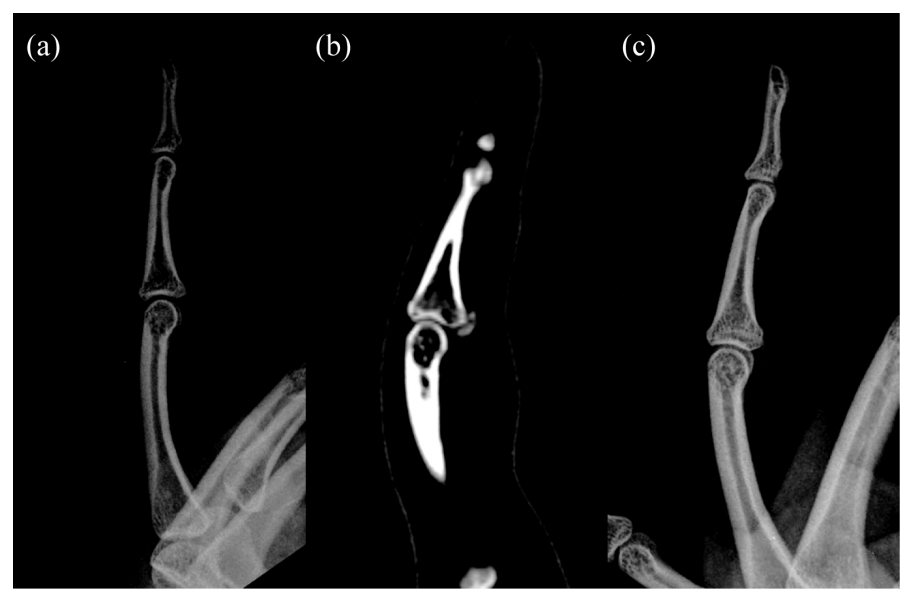

Figure 1. (a) Radiography of the 4th finger showing calcification in the FDS tendon close to the PIP joint; (b) Computed tomography showing round calcium deposit without association with the periosteum; (c) Radiography showing complete resolution of calcification after two weeks. 
could be used for immediate symptom relief. In many case reports in the literature [1] [3]-[5], unnecessary procedures were performed, and medications prescribed.

\section{Conclusion}

We report an unusual case of acute calcific tendinitis of the FDS insertion of the 4th finger in a young female martial art athlete after minor trauma history initially misdiagnosed it as a fracture. We expect that this case presentation will be helpful to others by increasing the awareness of acute calcific tendinitis of the finger to avoid unnecessary invasive diagnostic tests or treatments like surgery.

\section{References}

[1] Caroll, R.E., Sinton, W. and Garcia, A. (1955) Acute Calcium Deposits in the Hand. American Medical Association, 157, 422-426. http://dx.doi.org/10.1001/jama.1955.02950220016005

[2] Millon, S.J., Bush, D.C. and Harrington, T.M. (1993) Acute Calcific Tendinitis in a Child: A Case Report. Journal of Hand Surgery (American Volume), 18, 592-593. http://dx.doi.org/10.1016/0363-5023(93)90296-F

[3] Selby, C.L. (1984) Acute Calcific Tendinitis of the Hand: An Infrequently Recognized and Frequently Misdiagnosed Form of Periarthritis. Arthritis \& Rheumatism, 27, 337-340. http://dx.doi.org/10.1002/art.1780270314

[4] Yosipovitch, G. and Yosipovitch, Z. (1993) Acute Calcific Periarthritis of the Hand and Elbows in Women. A Study and Review of the Literature. The Journal of Rheumatology, 20, 1533-1538.

[5] Dilley, D.F. and Tonkin, M.A. (1991) Acute Calcific Tendinitis in the Hand and Wrist. Journal of Hand Surgery, 16, 215-216. http://dx.doi.org/10.1016/0266-7681(91)90181-M

[6] Huntley, J.S. and Dougall, T.W. (2003) Mistaken Identity: Calcific Tendinitis in the Finger. Hospital Medicine, 64, 747.

[7] Cohen, I. (1924) Calcareous Deposit at the Insertion of Flexor Carpi Ulnaris Tendon Following Trauma. The American Journal of Surgery, 38, 172-173.

[8] Gandee, R.W., Harrison, R.B. and Dee, P.M. (1979) Peritendinitis Calcarea of Flexor Carpi Ulnaris. AJR, 133, 11391141. http://dx.doi.org/10.2214/ajr.133.6.1139

[9] Ali, S.N. and Kelly, J.L. (2004) Acute Calcific Tendinitis of the Finger-A Case Report. Hand Surgery, 9, $105-107$. http://dx.doi.org/10.1142/S0218810404001954

[10] Uhthoff, H.K., Sarkar, K. and Maynard, J.A. (1976) Calcifiying Tendonitis. A New Consept of Its Pathogenesis. Clinical Orthopaedics and Related Research, 118, 164-168. 